\title{
Morphometric characterization of domestic rabbits (Oryctolagus cuniculus domesticus L.) in western Algeria
}

\author{
Mogharbi A ${ }^{1}$ * Mediouni M. R ${ }^{1}$, Ameur Ameur A². Azzi N². Gaouar S. B. S \\ ${ }^{1}$ PpBioNut Laboratory, Department of Biology, University of Tlemcen, Algeria \\ ${ }^{2}$ Department of Agronomic, University of Tlemcen, Algeria
}

*Corresponding Author: Mogharbi A. Email: amogharbi672@gmail.com

Article history: Received: Janauray $2^{\text {d }} 2021$; Revised: March $15^{\text {th }}$ 2021; Accepted: May $25^{\text {th }} 2021$

\begin{abstract}
In order to identify domestic rabbit populations in the departement of Tiaret, thirteen morphological descriptors were applied. This study was based only on the phenotypic variability, all breeds are were defined according to the international standards based on external appearance. quantitative traits were measured on 70 rabbits belonging to different agroecological localities (Steppic, Mountainous and Saharian). A comparison was carried out in order to identify differences and similarities between males and females. The baryometric characterization reveals a significant phenotypic diversity at the population studied. Multiple correspondence factor analysis (MCA) and ascending hierarchical classification (CAH) identified three distinguished classes. In general, the local rabbit has an average weight of $1.97 \mathrm{~kg}$, an average body length of $28.8 \mathrm{~cm}$ and a chest measurement of $26.11 \mathrm{~cm}$.
\end{abstract}

Keywords: Morphometry; Rabbit; Algeria; local popualtion .

\section{Introduction}

The rabbit named "European rabbit", whether wild or domestic, belongs to the species Oryctolagus cuniculus, it has been domesticated recently by contribution of other species such as the bovine and the dog whose domestication dates back to the prehistoric period, in addition, cuniculus domesticus has a set of properties that make it an animal of interest for studies that deals with the genetic diversity and population genetics (Hardy et al, 1994, Queney et al, 2000).

According to Berchiche and Kadi (2002), there was no study on the local rabbit before 1990, but rabbit farming has existed for a very long time in Algeria (Ait Taharet Fettal, 1990). It seems that the North African rabbit was introduced by the Romans across the Iberian Peninsula half a century BC and seems to have been maintained there as small rural herds (Barkok, 1990). In the 19th century, colonization, and the arrival of populations of European origin traditionally consuming rabbits more recently led to the development of rational units in the Maghreb, but this rational sector only appeared in Algeria at the beginning of the years. eighty (Colin and Lebas, 1995).

The rabbit species in Algeria are represented by the taxonomic family of Leporidae, which includes domestic rabbits (Oryctolagus cuniculus domesticus) and hares (Lepus capensis) or "the brown hare". Phenotypically resulting from untimely and sometimes voluntarist crossbreeding (search for performance traits) with foreign breeds introduced in Algeria during the 1970s, as part of certain rural development projects (the White New Zealand, the Fauve de Burgundy, the Giant of Flanders, the Californian and even the Giant of Spain). This process was aggravated by the introduction, between 1985 and 1989, of selected breeders (hybrids such as Hyla and Hyplus), intended for intensive breeding (Berchiche and Kadi, 2002; Ferrah et al., 2003; Othmani-Mecif and Benazzoug, 2005). 
These uncontrolled mixtures of breeds in Algeria create a situation of ambiguity on the ground that goes against the reasonable exploitation of this animal, so it is important to have an idea of the existing racial potential, consequently having an idea of the real potential on the field since each management and genetic improvement plan begins with a field surveys.

Actually, there is no typical, morphometric, biochemical and zootechnical plan for Algerian rabbits to be developed. In this context, this study is deployed in the purpose of identifying some local rabbit potentials at the level of the department of Tiaret, which is located in the highlands of western Algeria. This identification study was based on a morphometric characterization of the animals and a survey by using a questionnaire to get an idea of the typology of breeding of the species at the level of the Tiaret province

\section{Materials and methods}

\section{Study area}

The study used a descriptive survey designed according to the French Federation of Cuniculiculture (FFC) and carried out on 70 adult healthy individual rabbits from Tiaret province, which is, located north Algeria. It characterized by cold harsh winter and hot summer. The study area is subdivided into 3 distinct regions the first is the mountain region; the second is the Sahara and the third is the steppe. The duration of the study took place from August until December 2019

A total of 70 rabbits including 27 males and 43 females (table 1) from different locations are studied, selected rabbits were clinically healthy and in good body conformation

Table 1. Distribution of samples by region and sex.

\begin{tabular}{lllll}
\hline District & Agroecological regions & Males & Females & Total \\
\hline Faija & \multirow{2}{*}{ mountain } & 5 & 9 & 14 \\
\hline Tagdemet & Sahara & 4 & 13 & 17 \\
\hline Aindheb & \multirow{2}{*}{ steppe } & 10 & 3 & 13 \\
\hline Sougueur & & 6 & 10 & 16 \\
Tousnina & & 2 & 8 & 10 \\
\hline Total & & 27 & 43 & 70 \\
\hline
\end{tabular}

For this study, a tape measure was used to measure the parameters related to the lengths (except the ear and the legs). A metric tape measure to measure the ear and legs. A scale to weigh the rabbit.

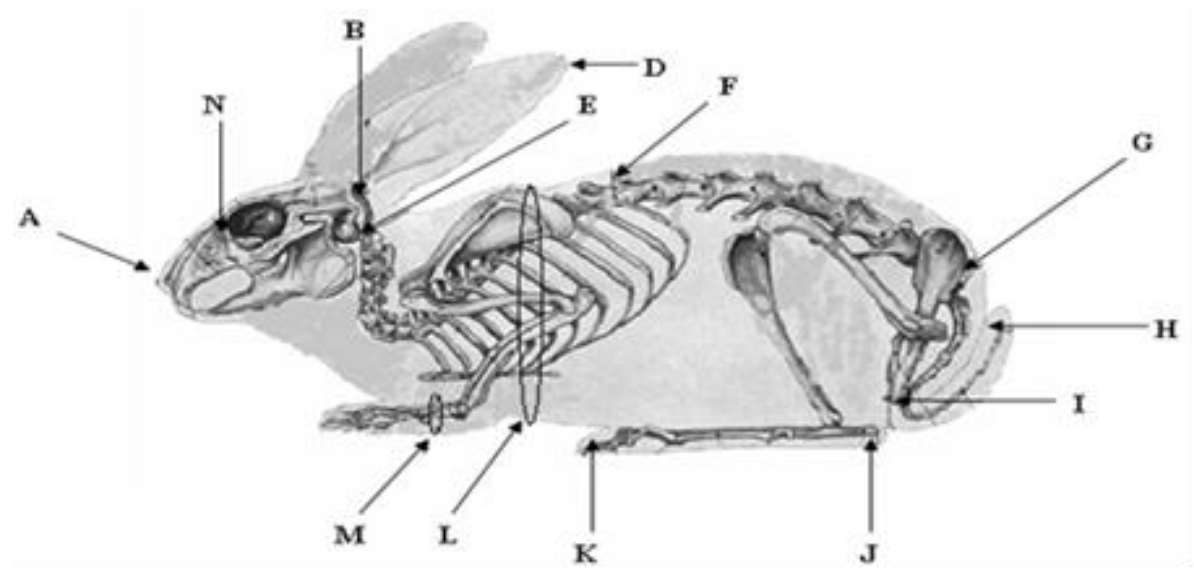

Figure 1. The landmarks used in the study to define the morphological parameters of lengths and circumferences in rabbits (Nezzar, 2007). 
Table 2. The benchmarks used for the definition of the morphological parameters measured in the study (Nezar, 2007).

\begin{tabular}{l|l}
\hline Point & Definition \\
\hline A & The tip of the nose \\
B & Occipital protuberance \\
C & Base of the ear \\
D & Apex of the auricular pinna (tip of the ear) \\
E & Atlanto-occipital joint \\
F & Thoraco-lumbar joint \\
G & Lumbosacral joint \\
H & Last caudal vertebra \\
I & Base of the tail \\
J & Point of the heel \\
K & End of the claw \\
L & A point of the thorax diameter \\
$\mathrm{M}$ & Middle of the axes of the metacarpals \\
$\mathrm{N}$ & Internal angle of the eye \\
\hline
\end{tabular}

To carry out all the measurements, the rabbit is kept immobilized, on a horizontal plane, after which we took the various measurements in $\mathrm{cm}$, after locating the landmarks on the surface of the animal's body (Figure 2). These points help to define the measured parameters mentioned in the table (table 02). For weight gain, a commercial scale was used. To reduce measurement errors, we repeated the measurements several times

The parameters measured are quantitative and qualitative. The quantitative parameters are LTOT, LTET, DY, LCORP, LMA, LMP, LLOMB, TP, T LOMB, TMA, TMP, live weight and age, the definition of these parameters and reported in Table 3. For females we also counted the number of pacifiers and the number of births per career. Qualitative parameters are represented by body conformation, coat color and eye color.

Table 3. Definition of parameters measured in the study

\begin{tabular}{|c|c|c|}
\hline Abbreviation & Parameter & Definition \\
\hline $\begin{array}{l}\text { LCORPS } \\
(\mathrm{cm})\end{array}$ & The length of the body & $\begin{array}{l}\text { Measured at the midline of the body, between (E) and } \\
\text { (I), while following the profile of the spine. }\end{array}$ \\
\hline LTET (cm) & The length of the head & $\begin{array}{l}\text { Measured at the center line of the head, between (A) and } \\
\text { (B). }\end{array}$ \\
\hline LTOT $(\mathrm{cm})$ & The total length & $\begin{array}{l}\text { Total length of the animal (tail excluded), measured } \\
\text { between (A) and (I). }\end{array}$ \\
\hline DY $(\mathrm{cm})$ & The distance between the eyes & The distance between the internal angles eyes $(\mathrm{N})$. \\
\hline $\operatorname{LLOMB}(\mathrm{cm})$ & The length of the lower back & $\begin{array}{l}\text { Measured between }(\mathrm{F}) \text { and }(\mathrm{G}) \text { while according to the } \\
\text { profile of the column vertebral. }\end{array}$ \\
\hline TLOMB $(\mathrm{cm})$ & Circumference of the lumbar region & This is the average width of the region Lumbar. \\
\hline $\begin{array}{l}\text { TR POIT } \\
(\mathrm{cm})\end{array}$ & Chest measurement & $\begin{array}{l}\text { Measured just behind the shoulders, the metric tape runs } \\
\text { vertically in back of the scapulae (L). }\end{array}$ \\
\hline TMA $(\mathrm{cm})$ & Circumference of the forelimb & $\begin{array}{l}\text { This is the diameter of the middle of the limb anterior, } \\
\text { measured at }(\mathrm{M}) \text {. }\end{array}$ \\
\hline $\mathrm{LO}(\mathrm{cm})$ & Length of ear & Measured between (C) and (D). \\
\hline LargO $(\mathrm{cm})$ & Width of the ear & Measured at the level of the largest width of the ear. \\
\hline $\mathrm{LP}(\mathrm{cm})$ & Leg length & Measured between $(\mathrm{J})$ and $(\mathrm{K})$. \\
\hline
\end{tabular}

\section{Results and discussion}

The field survey

\section{Breeding typology}

The survey that was developed for this study allowed us to collect some important informations concerning the typology and structure of rabbit farming in the province of Tiaret. 
Starting from this survey, we found that the owners of rabbit farms are generally male ( $80 \%$ of the surveyed farms ). The breeders of the region do not attach great importance to the habitat of the animals. The latter are reared in rudimentary enclosures designed for the breeding of their animals (Figure 3).

The feed for rabbits varied from vegetables to concentrated granulated feed. Some herders depend on pasture to provide food for the animals. All herders rely on traditional methods for watering animals. They use plates or containers to provide water to the rabbits. The mode of reproduction is represented by natural control in all the farms visited, artificial insemination is absent from the practices of the breeders due to its expansive cost. We also noticed during our field survey that breeders do not vaccinate animals.

In a study carried out by Abdelli Fatiha (2016) in a region of the highlands of eastern Algeria (M'sila, Batna, Setif) shows that farms were in some vert bad conditions and knows several problems that prevent its development. The most important of these problems is the lack of specific feed and the technical non-qualification of the majority of breeders. However, this study reveals that some units have a herd exceeding 200 females. The most widely adopted farming system is semi-intensive. Production performance remains relatively modest given the weaning-slaughter mortality (5 to $10 \%$ ) with a weaning productivity of 8 young rabbits / litter.

In another similar study in the region of Abidjan (Ivory Coast), the results showed that rabbit farming is a developing breed. However, in $95 \%$ of cases, rabbit farming is considered a secondary activity and is mainly exercised by the male gender at $84.76 \%$. The farms in this region are mainly located in urban areas. The most practiced mode of reproduction is the extensive mode, with four (4) farrowing per year and six (6) young rabbits on average per farrowing. The different breeding systems is made up of an artisanal or family system in $42.96 \%$ of cases, an improved artisanal system in $38.86 \%$ of cases and
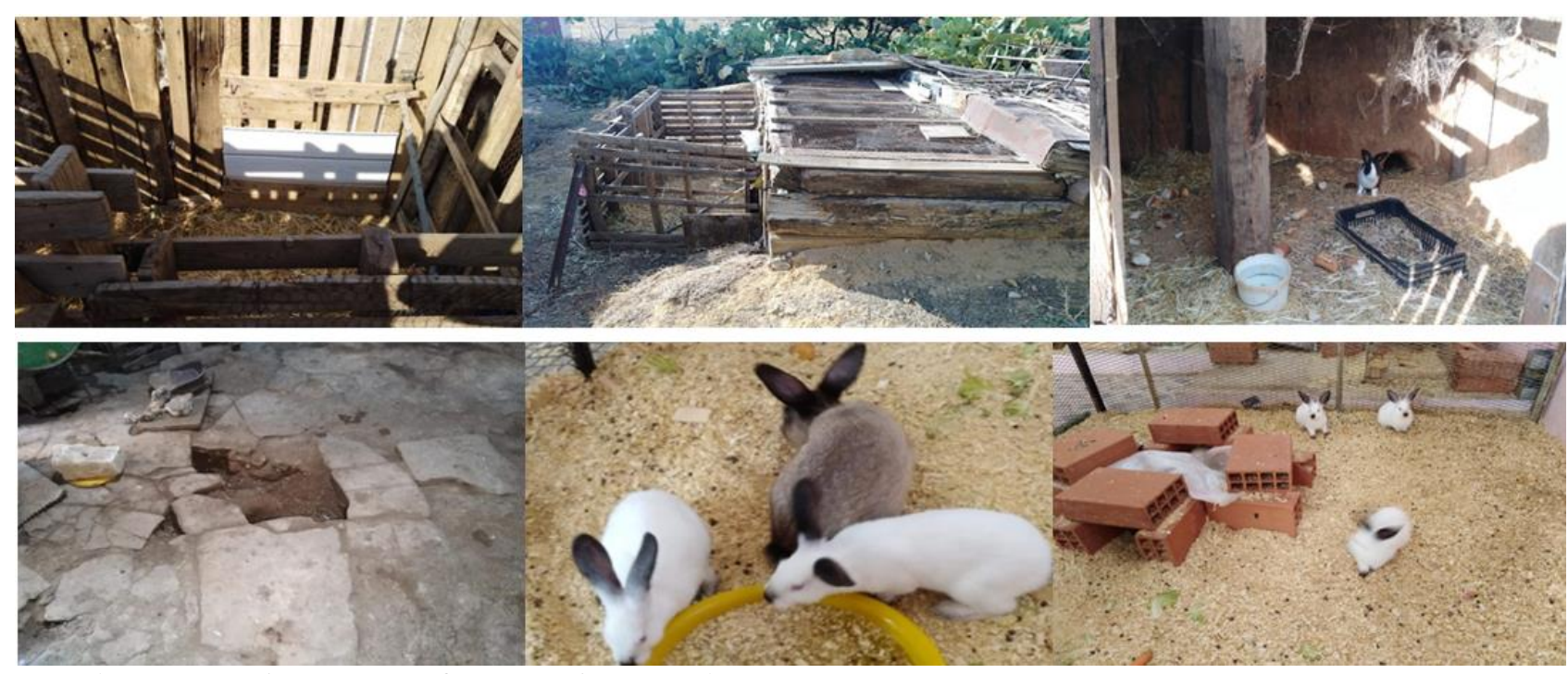

a modern system in $18.18 \%$ of cases (Kimse et al., 2017).

Figure 2. Different types of habitat of the domestic rabbit in the Tiaret region (original photo).

\section{Morphometric characterization}

Descriptive analysis was used to estimate for each ecotype as well as for the total population, the frequencies of qualitative traits and the mean, and standard deviation of quantitative traits. 
Mogharbi et al, 2021. Genet. Biodiv. J , 5 (2) ; 72-97

Table 4. Descriptive analysis of body measurements in domestic rabbits in the Tiaret willaya.

\begin{tabular}{llllll} 
& Mean & Standard deviation & Variance & Min & Max \\
\hline L TOT $(\mathrm{cm})$ & 41.84 & 6.68 & 65.26 & 20 & 57 \\
\hline L TET $(\mathrm{cm})$ & 14.17 & 2.39 & 8.21 & 6 & 21 \\
\hline DY $(\mathrm{cm})$ & 5.1 & 0.76 & 1.02 & 3 & 8 \\
\hline L CORP $(\mathrm{cm})$ & 28.80 & 5.97 & 50.76 & 12 & 46 \\
\hline TR POIT $(\mathrm{cm})$ & 26.11 & 5.47 & 44.22 & 11 & 39 \\
\hline T LOMB $(\mathrm{cm})$ & 22.09 & 4.28 & 27.1 & 12 & 36 \\
\hline L LOMB $(\mathrm{cm})$ & 10.92 & 1.62 & 4.24 & 4 & 14 \\
\hline TR MBP $(\mathrm{cm})$ & 5.09 & 0.87 & 1.24 & 3 & 9 \\
\hline LMA $(\mathrm{cm})$ & 10.51 & 1.14 & 2.67 & 3 & 13 \\
\hline TMA $(\mathrm{cm})$ & 5.13 & 1.02 & 1.79 & 2 & 9 \\
\hline LP $(\mathrm{cm})$ & 12.31 & 1.15 & 2.06 & 7 & 4 \\
\hline POIDS kg & 1.97 & 0.48 & 0.52 & 0.5 & 8 \\
\hline AGE $(\mathrm{mois})$ & 3.40 & 1.76 & 3.98 & 0 & 14 \\
\hline LO $(\mathrm{cm})$ & 10.59 & 1.04 & 2 & 5 & 6 \\
\hline larg $(\mathrm{cm})$ & 4.04 & 0.41 & 0.40 & 3 & 4 \\
\hline
\end{tabular}

According to the results of the descriptive analysis on the animals of the Tiaret region, it appears that the latter shares the same criteria with the population of Batna (Nezzar, 2007), in particular for the LO and TPOIT, TMA and TP characters, but distinct from the Tlemcen populations (Meghraoui, 2018).

The PCA analysis carried out by the software (R version 3.4.3) on 14 active morphometric variables in association with two additional variables (Age and weight) and two additional qualitative variables (regions and sex), presents a rate of inertia or total variability of $57.65 \%$, shared on two axes (figure 4). The variables are organized in 3 groups; we notice that the parameters TLOMB, DY, TR POIT, LCORP, LO, LP, LTET, AGE, WEIGHT, LTOT, largO, are positively correlated with each other and form a group (black circle). The TMA, TR MBP parameters are positively correlated with each other and form a second group (red circle). Finally, the blue circle represents the LMA and LLOMB parameters, which are also positively correlated with each other.

Demonstrating such a correlation is important from a zootechnical and genetic improvement perspective, because having an idea of a single trait allows us to extrapolate it to all traits of the same correlation group.

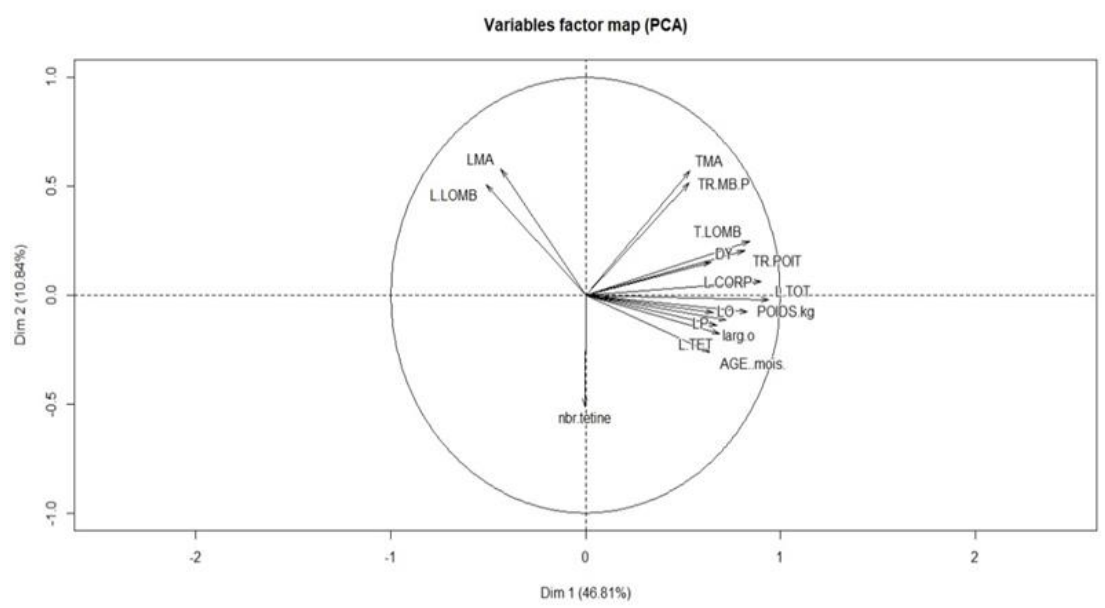

Figure 3. Graphical representation of quantitative variables by PCA. 
The HAC analysis is carried out on the population of the 5 studied regions of the province of Tiaret, this analysis represents a rate of inertia or total variability of $57.65 \%$, divided into two axes: Axis 1 $(46.81 \%)$ and axis $2(10.84 \%)$.

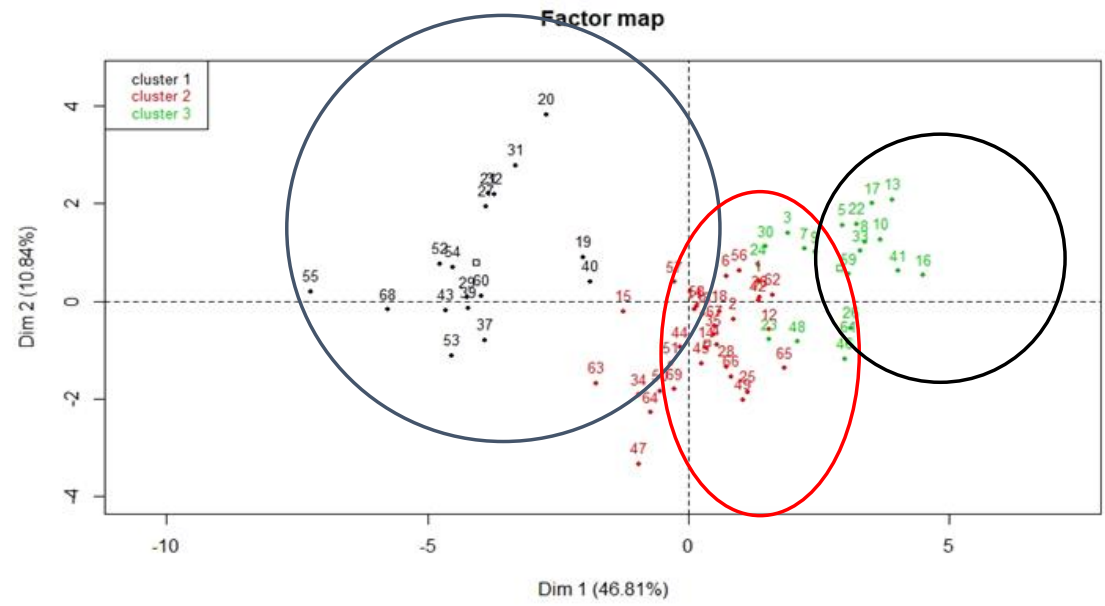

Figure 4. Distribution of individuals by HAC

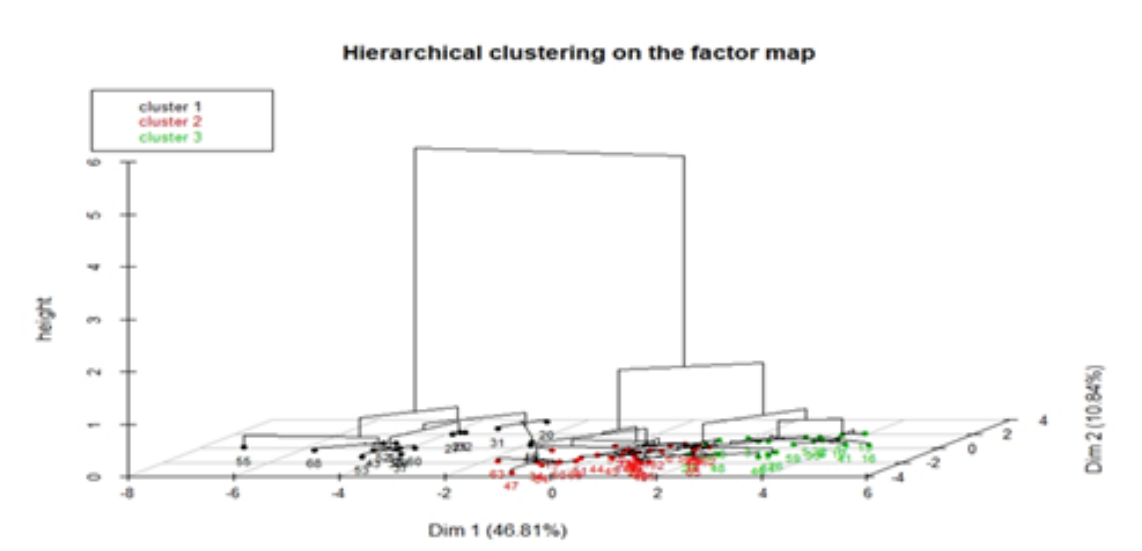

Figure 5. Graphic representation of individuals by $\mathrm{CAH}$ in 3D.

The graphic representation of the $\mathrm{CAH}$ (figures 5 and 6) allowed us to group the individuals of the region studied into 3 groups.

Cluster 1: represents individuals who carry high values for the morphometric parameters TLOMB, DY, TR POIT, L CORP, LO, LP, LTET, AGE, WEIGHT, LTOT and largO, and low values for the morphometric parameters TMA and TRMBP.

Cluster 2: this is a balanced group, its individuals carry mean values for the morphometric parameters TLOMB, DY, TRPOIT, LCORP, LO, LP, LTET, AGE, POIDS, LTOT, largo, TMA and TRMBP. 
Cluster 3: is represented by individuals who bear low values for the morphometric parameters TMA and TRMBP, and express low values for the parameters TLOMB, DY, TRPOIT, LCORP, LO, LP, LTET, AGE, WEIGHT, LTOT, largo, TMA and TRMBP.

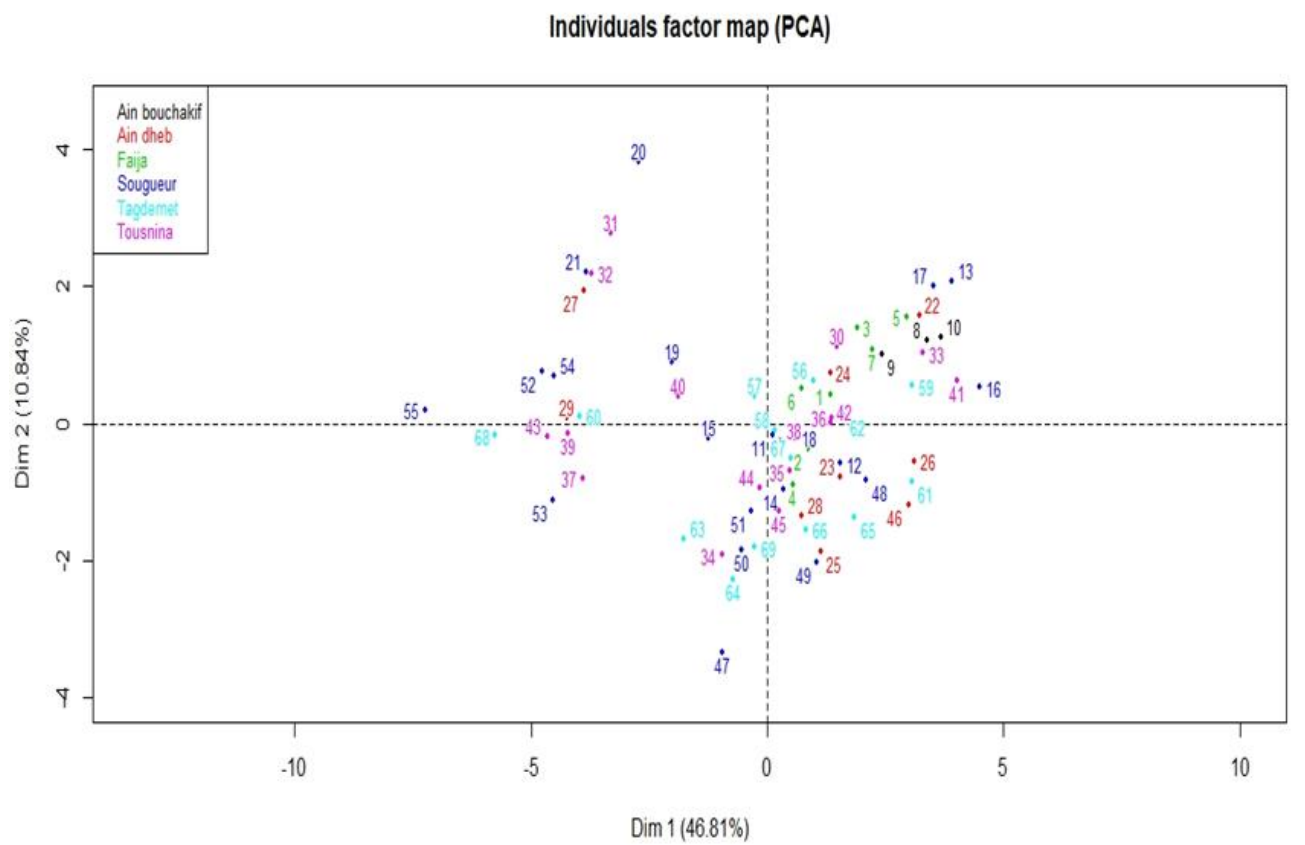

Figure 6. Graphic representation of individuals by the PCA.

The first 2 axes of this PCA (Figure 7) represent $57.65 \%$ of the total inertia. Which is statistically very significant. Two groups emerge from this PCA, the first group (black circle) includes mountain animals (Faija and Tagdemet), steppe (Sougueur and Tousnina) and Sahara (Ain dheb). The second group (red circle) is represented by individuals from the regions of Tagdemet (mountain), Sougueur and Tousnina (steppe) and Aindheb (Sahara).

We noticed from this result that the agroecological region has no effect on the genetic structure of the population to be studied and that the difference observed is only a reflection of the farming system and / or the specific genetic heritage of each animal.

\section{Conclusion and perspectives}

During our work, a field survey supported by a questionnaire was developed to collect informations on the typology of breeding in the departement of Tiaret, we also contributed to the morphometric characterization of this population at three different agroecological zones. Our field investigation revealed to us that breeding in the studied region is completely traditional. The breeders are $80 \%$ male and $20 \%$ female.

The originality of this work, was depending on achieving valuable knowledges about a local rabbit populations originating from the Tiaret region, this could allowed us to show that the local rabbit is characterized by an average adult weight of $1.97 \mathrm{~kg}$ making it possible to classify the population in the category of light rabbit breeds. This rabbit has a medium length body $(28.8 \mathrm{~cm})$ with a shallow thorax $(26.11 \mathrm{~cm})$, well developed loins, good average lumbar width $(22.09 \mathrm{~cm})$ and a good height hindquarter. The local rabbit has overall a low live weight.

We also notice at the level of this study that there is no structuring of these populations according to the region; mountain (Faija, Tagdemet), steppe (Sougueur and Tousnina) and Sahara (Aindheb). We note therefore that there is a homogeneity between the individuals of the study regions probably due to the uncontrolled mixing practiced by the breeders. 


\section{References}

Abdelli F. 2016. Elevage du lapin dans quelques wilayas des hauts plateaux (M'sila, Batna, Setif). Mémmoire de fin d'étude, Université Mouloud Mammeri de Tizi-Ouzou,

Ait Tahar H. Fettal M. 1990. Témoignage sur la production et l'élevage du lapin en Algérie. 2ème conférence sur la production et la génétique du lapin dans la région méditerranéenne, Zagazig (Egypte) ,3 -7 septembre.

Barkok A. 1990. Quelques aspects de l'élevage du lapin au Maroc. Options méditerranéennes : Série A, $\mathrm{n}^{\circ} 17, \mathrm{pp} 19-22$.

Berchiche M. Kadi SA. 2002. The kabyle rabbits (Algeria). Rabbit Genetic Resources in Mediterranean Countrie.

Colin M. Lebas F. 1995. Le lapin dans le monde.AFC éditeur Lempdes, 330 pp

Ferrah A. Yahiaoui S. Kaci A. Kabli L. 2003. Les Races De Petits Elevages (Aviculture, Cuniculture, Apiculture, Pisciculture).Recueil des Communications Atelier $\mathrm{N}^{\circ} 3$ «Biodiversité Importante pour l'Agriculture» MATEGEF/ PNUD Projet ALG/97/G31.tome X.52-61.

FFC 2000. Les races de lapins. Spécificités zoologiques, Standards officiels. Fédération Française de Cuniculiculture éditeur, Paris, 288p.

Hardy C. Casane D. Vigne JD. Callou C. Dennebouy N. Mounolou JC. Monnerot M. 1994. Ancient DNA from Bronze Age bones of European rabbit (Oryctolagus cuniculus). Experientia. 15;50(6):564-70.

Kimse M. Coulibaly KAS. Gnanda BI. Zongo M. Yapi YM. fantodji TA. Otchoumou AA. 2017. Caracterisation des systemes d'elevage cunicole dans le district d'abidjan (cote d'ivoire). Agronomie Africaine 29 (2) : 185 - 196.

Meghraoui M. 2018. Identification et caractèrisation morphométrique de quelques populations de lapin domestique au niveau de la wilaya de Tlemcen. Mémmoire de licence, Université de Tlemcen. PP 100

Nezar N. 2007. Caractéristique morphologique du lapin locale. Mémoire de fin d'étude.

Othmani-Mecif K. Benazzoug Y. 2005. Caractérisation de certains paramètres biochimiques plasmatiques et histologiques (tractus génital femelle) chez la population locale de lapin (Orygtolaguscuniculus) non gestante et au cours de la gestation. Sciences et technologie $\mathrm{C}-\mathrm{N}^{\circ} 23$, pp.91-96.

Queney G.Ferrand N. Marchandeau S. Azevedo M. Mougel F Branco M. Monnerot M 2000. Absence of a genetic bottleneck in a wild rabbit (Oryctolagus cuniculus) population exposed to a severe viral epizootic. Mol Ecol. 9(9):1253-64. 